\title{
miR-145 suppresses the proliferation, invasion and migration of NSCLC cells by regulating the BAX/BCL-2 ratio and the caspase-3 cascade
}

\author{
YI PAN $^{1 *}$, CONGLIN YE $^{2 *}$, QINGSHAN TIAN $^{3}$, SONGXIN YAN $^{4}$, XIAOPING ZENG $^{1}$, \\ $\mathrm{CHU}^{\mathrm{XIAO}}{ }^{1}$, LINGYUN WANG $^{1}$ and HONGMEI WANG ${ }^{1}$
}

\begin{abstract}
${ }^{1}$ School of Basic Medical Sciences, Nanchang University; ${ }^{2}$ Department of Orthopedics, Artificial Joints Engineering and Technology Research Center of Jiangxi Province; ${ }^{3}$ Department of Cardiology, The First Affiliated Hospital of Nanchang University; ${ }^{4}$ Medical College of Nanchang University, Nanchang, Jiangxi 330006, P.R. China
\end{abstract}

Received June 15, 2017; Accepted November 23, 2017

DOI: $10.3892 / \mathrm{ol} .2018 .7863$

\begin{abstract}
Although microRNA (miR)-145 has been identified to be a tumor suppressor in various types of tumor, it promotes the progression of non-small cell lung cancer (NSCLC). However, the precise underlying molecular mechanism of its action remains unclear. The present study investigated the effects of miR-145 on the proliferation, invasion, metastasis and apoptosis of the NSCLC A549 cell line and the underlying molecular mechanism of its action. In vitro cell proliferation, invasion, migration and apoptosis assays were employed, and the expression levels of matrix metalloproteinase (MMP)-2, MMP-9, B-cell lymphoma 2 (Bcl-2), Bcl-2-associated X protein (Bax), caspase-3and poly(ADP-ribose) polymerase (PARP) were evaluated by western blot analysis. The results demonstrated that ectopic expression of miR-145 inhibited the proliferation, invasion and migration of A549 cells, but promoted the apoptosis of A549 cells. Western blot analysis indicated that increased miR-145 levels led to a marked decrease in the expression of MMP-2, MMP-9 and Bcl-2. Upregulation of miR-145 expression increased the expression of Bax, thus increasing the $\mathrm{Bax} / \mathrm{Bcl}-2$ ratio. Additionally, the results indicated that miR-145 over expression promoted the cleavage of caspase- 3 and PARP. Taken together, these results
\end{abstract}

Correspondence to: Professor Hongmei Wang, School of Basic Medical Sciences, Nanchang University, 461 Bayi Road, Nanchang, Jiangxi 330006, P.R. China

E-mail: wanghongmay@hotmail.com

*Contributed equally

Abbreviations: NSCLC, non-small cell lung cancer; miR, microRNA; FBS, fetal bovine serum; HRP, horseradish peroxidase; $\mathrm{SD}$, standard deviation

Key words: non-small cell lung cancer, proliferation, invasion, migration, B-cell lymphoma 2-associated $\mathrm{X}$ protein/B-cell lymphoma 2 ratio indicated that miR-145 suppresses the proliferative, invasive and migratory ability of A549 cells. Additionally, miR-145 upregulation induced apoptosis of A549 cells possibly by decreasing MMP-2 and MMP-9 expression, the Bax/Bcl-2 ratio and the activity of the caspase- 3 cascade.

\section{Introduction}

Non-small cell lung cancer (NSCLC) accounts for between 80 and $85 \%$ of cases of lung cancer, a leading cause of mortality worldwide (1). Despite advances in the diagnosis and treatment of lung cancer over the last few decades, the majority of patients are diagnosed only at advanced stages, and the overall prognosis of patients with NSCLC remains poor (2). Therefore, it is crucial to understand the underlying mechanisms of disease progression and to identify new therapeutic targets for NSCLC.

MicroRNAs (miRNAs or miRs) are a class of small non-coding RNAs of between 18 and 25 nucleotides in length that bind to the 3'-untranslated region of mRNAs, thus resulting in mRNA degradation or in decreased gene expression at the post-transcriptional level (3). Emerging evidence has revealed that miRNAs contribute to the regulation of diverse cellular functions and that deregulation of miRNA expression is often associated with a variety of disorders including human malignancies $(4,5)$. miR-145 has been identified as a tumor suppressor that is downregulated in various types of cancer, including prostate (6), ovarian (7), bladder (8) and colon (9-11) cancer. miR-145 has also been reported to be involved in the progression of NSCLC (12-14). However, the molecular mechanism underlying the effects of miR-145 on the biological progression of NSCLC is not well understood.

In the present study, the effects of miR-145 on the proliferation, invasion, migration and apoptosis of NSCLC A549 cells were investigated. The results indicated that increased miR-145 expression inhibited the proliferation, invasion and migration of, and induced morphological changes in, NSCLC A549 cells. Furthermore, the upregulation of miR-145 activated the caspase- 3 cascade. These results suggest that miR-145 serves 
an important function in NSCLC progression and thus may be a promising target for the treatment of NSCLC.

\section{Materials and methods}

Reagents. The human NSCLC cell line A549 was purchased from the American Type Culture Collection (Manassas, VA, USA). RPMI-1640 medium, fetal bovine serum (FBS), PBS, bovine serum albumin (BSA), dimethylsulfoxide and Cell Counting Kit-8 (CCK-8) were purchased from Beijing Transgen Biotech Co., Ltd. (Beijing, China). Antibodies against matrix metalloproteinase (MMP)-2, MMP-9, B-cell lymphoma 2 (Bcl-2), Bcl-2-associated X protein (Bax), caspase-3, poly (ADP-ribose) polymerase (PARP), $\beta$-actin and horseradish peroxidase (HRP)-conjugated secondary antibodies were purchased from Cell Signaling Technology, Inc. (Danvers, MA, USA). Lipofectamine ${ }^{\circledR} 2000$ and Opti-MEM were purchased from Invitrogen; Thermo Fisher Scientific, Inc. (Waltham, MA, USA). AnnexinV/fluorescein isothiocyanate (FITC) kit and Matrigel invasion chambers were purchased from BD Biosciences (San Jose, CA, USA). The Transwell invasion chambers were purchased from Costar (Corning Life Sciences, Cambridge, MA, USA). Crystal violet staining solution was purchased from Beyotime Institute of Biotechnology (Haimen, China). Scrambled sequence and miR-145 mimic were purchased from Biotend (Shanghai, China).

Cell culture and transfection. The A549 cells were grown in RPMI-1640 medium supplemented with 10\% FBS, $100 \mathrm{U} / \mathrm{ml}$ penicillin and $100 \mu \mathrm{g} / \mathrm{ml}$ streptomycin, and were cultured at $37^{\circ} \mathrm{C}$ in a humidified atmosphere containing $5 \% \mathrm{CO}_{2}$. All cells used in the present study were subjected to $<20$ passages.

In the exponential phase, A549 cells were seeded at a density of $5 \times 10^{5}$ cells/well in a 6 -well plate for $24 \mathrm{~h}$ before transfection. Lipofectamine 2000 was used for the transfection of scrambled sequence: Forward, 5'-UUCUCCGAACGU GUCACGUTT-3' and reverse, 5'-ACGUGACACGUUCGG AGAATT-3'; or miR-145 mimic, forward, 5'-GUCCAGUUU UCCCAGGAAUCCCU-3' and reverse, 5'-GGAUUCCUG GGAAAACUGGACUU-3', according to the manufacturer's protocol. A final concentration of $100 \mathrm{nM}$ miR-145 mimics and $100 \mathrm{nM}$ negative control miRNA was used for transfection. At 24 or $48 \mathrm{~h}$, the transfected cells were collected and used in the subsequent experiments.

Cell proliferation assay. Cell proliferation was detected using the CCK-8 assay. Briefly, A549 cells were transfected with scrambled sequence or miR-145 mimic. Transfected and non-transfected cells were incubated in 96-well plates at a density of $4 \times 10^{3}$ cells/well. At 24,48 and $72 \mathrm{~h}$ post-transfection, CCK-8 solution was added ( $10 \mu \mathrm{l} /$ well) and cells were incubated at $37^{\circ} \mathrm{C}$ for $2 \mathrm{~h}$. Absorbance at $450 \mathrm{~nm}$ was measured using a Universal Microplate Reader EL800 (Bio-Tek instruments, Inc., Vermont, MA, USA).

Boyden chamber transwell assays. For the invasion assays, $5 \times 10^{4}$ cells were plated in a $8.0 \mu \mathrm{m}$ pore size Matrigel invasion chamber without serum and the lower chamber contained RPMI-1640 supplemented with $20 \%$ FBS that acted as a chemoattractant. At $24 \mathrm{~h}$, the non-invading cells were removed with cotton swabs. The invasive cells located on the lower side of the chamber were fixed in $4 \%$ formaldehydeat room temperature for $15 \mathrm{~min}$, stained with $0.2 \%$ crystal violet staining solution at room temperature for $30 \mathrm{~min}$ and counted under a phase-contrast microscope (Olympus Corporation, Tokyo, Japan) in three random fields (magnification, x100).

Wound healing assays. The migration of the A549 cells was evaluated using wound-healing assays. Cells $\left(5 \times 10^{5}\right.$ cells cells/well) from the three groups $(\mathrm{CON}$, non-transfected control; NC, non-specific negative control; and MIMIC, miR-145 mimic) seeded in a 6-well culture plate to form a confluent monolayer and were then wounded using $100 \mu \mathrm{l}$ pipette tips. The scratch wounds were observed, and images were captured at 0 and $24 \mathrm{~h}$, under a phase-contrast microscope (magnification, $\mathrm{x} 40$ ).

Hoechst 33258 staining of the A549 cells. At $48 \mathrm{~h}$ post-transfection, A549 cells from the three groups (CON, non-transfected control; NC, non-specific negative control; and MIMIC, miR-145 mimic) were seeded in 6-well plates and fixed with $4 \%$ paraformaldehyde for $10 \mathrm{~min}$ at $4^{\circ} \mathrm{C}$. Subsequently, cells were washed three times with ice-cold PBS and stained with $10 \mathrm{mg} / \mathrm{l} \mathrm{Hoechst} 33258$ for $10 \mathrm{~min}$ at $25^{\circ} \mathrm{C}$ in the dark. Nuclei were observed under a fluorescence microscope (Olympus Corporation, Tokyo, Japan) (magnification, x200).

Cell apoptosis analysis. The cell apoptosis assays were performed using an Annexin-V/FITC kit. Cell apoptosis was detected using flow cytometry at $48 \mathrm{~h}$ after transfection. The transfected cells were collected and washed with ice-cold PBS prior to being stained with Annexin-V/FITC and propidium iodide (PI) solution for $15 \mathrm{~min}$ in the dark. The proportion of the apoptotic cells was determined using a flow cytometer (BD Biosciences, San Jose, CA, USA) and data were analyzed using FlowJo software (version 10; Tree Star, Inc., Ashland, OR, USA). All experiments were performed three times.

Western blot analysis. At $48 \mathrm{~h}$ post-transfection, cells from the three groups (CON, non-transfected control; NC, non-specific negative control; and MIMIC, miR-145 mimic) were collected and lysed in radioimmunoprecipitation assay buffer containing phenylmethanesulfonyl fluoride and phosphatase inhibitor cocktail (Applygen Technologies Inc., Beijing, China). Each sample was centrifuged at $17,105.6 \mathrm{x}$ for $10 \mathrm{~min}$ at $4^{\circ} \mathrm{C}$ to remove cell debris and the supernatant was collected for immune blotting. Protein concentrations were calculated using BSA. Equal quantities of proteins $(40 \mu \mathrm{g})$ were loaded and separated by SDS-PAGE (10\% gels) for $2 \mathrm{~h}$ at $100 \mathrm{~V}$ under reducing conditions. The proteins were transferred onto polyvinylidene difluoride membranes in a Tris-glycine transfer buffer. Subsequent to blocking with 5\% skim milk in Tris-buffered saline containing 0.1\% Tween-20 (TBST) at room temperature for $2 \mathrm{~h}$, the membrane was incubated with primary antibodies at $4^{\circ} \mathrm{C}$ overnight. The primary antibodies were: Anti-Bax (cat. no. 2774), anti-Bcl-2 (cat. no. 2872), anti-caspase-3 (cat. no. 9662), anti-PARP (cat. no. 9542), anti-MMP-2 (cat. no. 4022), anti-MMP-9 (cat. no. 3852) and $\beta$-actin (cat. no. 8457; dilution of all, 1:1,000). The membranes 
A



$\mathrm{D}$



B

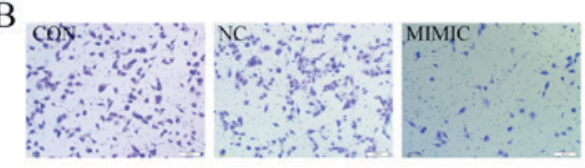

$\mathrm{C}$

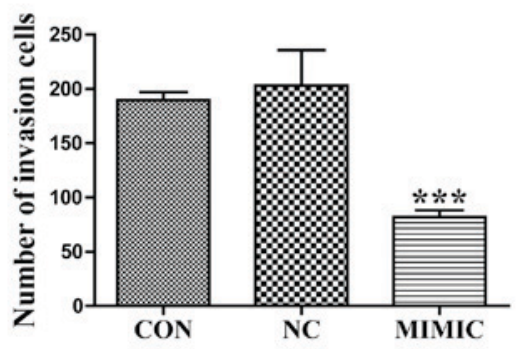

$\mathrm{E}$

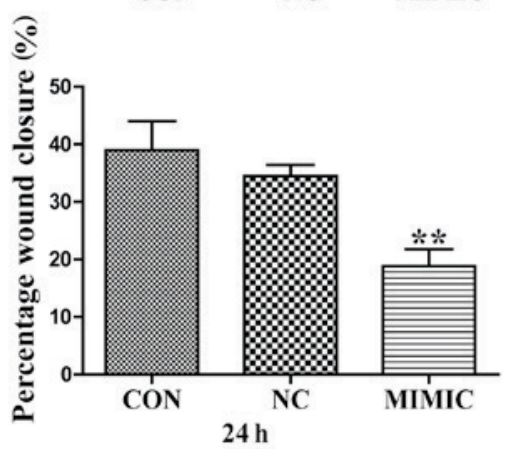

Figure 1. Increased miR-145 expression inhibits the proliferation, invasion and migration of A549 cells. (A) Increased miR-145 expression significantly inhibited the proliferation of A549 cells $\left({ }^{*} \mathrm{P}<0.05,{ }^{* *} \mathrm{P}<0.01,{ }^{* * *} \mathrm{P}<0.001\right.$ vs. CON). (B) Effects of ectopic expression of miR-145 on the migration of A549 cells. (C) Abnormal miR-145 expression significantly repressed the number ofinvasive A549 cells (scale bar, $100 \mu \mathrm{m}$; magnification, $\mathrm{x} 100$; ${ }^{* * *} \mathrm{P}<0.001 \mathrm{vs}$. CON). (D) Wound healing assay. Gap length of theinitial $(0 \mathrm{~h})$ and the residual gap length of $24 \mathrm{~h}$ after wounding were analyzed from photomicrographs. (E) miR-145 over expression significantly suppressed the percentage of wound closure in A549 cells (magnification, $\mathrm{x} 40)\left({ }^{* *} \mathrm{P}<0.01 \mathrm{vs}\right.$. CON). miR-145, microRNA-145; CON, non-transfected group; NC, non-specific negative control; and MIMIC, miR-145 mimic; OD, optical density.

were washed with Tris-buffered saline with Tween-20 (TBST) three times and incubated with secondary HRP-conjugated antibodies (Anti-rabbit IgG; cat. no. 7074; dilution, 1:5,000) at $25^{\circ} \mathrm{C}$ for $2 \mathrm{~h}$. Membranes were washed with TBST three more times and immune reactive protein bands were detected by an enhanced chemiluminescence kit (Beijing Trans gen Biotech Co., Ltd., Beijing, China). Image Quant TL 7.0 software (GE Healthcare, Chicago, IL, USA) was employed to quantify protein expression levels.

Statistical analysis. Data were analyzed using SPSS software (version 19.0; IBM Corp., Armonk, NY, USA). Data are expressed as the mean \pm standard deviation. Statistical analysis was performed using independent two-sample t-tests, or by one-way analysis of variance (ANOVA) with Tukey's post-hoc test for $\geq 3$ groups. $\mathrm{P}<0.05$ was considered to indicate a statistically significant difference.

\section{Results}

Upregulation of miR-145 expression inhibits the proliferation of A549 cells. A549 cells were transfected with scrambled sequence or miR-145 mimic, and their proliferative ability was assessed using a CCK-8 assay. At 24, 48 and $72 \mathrm{~h}$ post-transfection, the optical density values of the miR-145 mimic group, the non-transfected group, and non-specific negative control were $0.335 \pm 0.012,0.426 \pm 0.002$ and $0.349 \pm 0.048 ; 0.704 \pm 0.008,0.928 \pm 0.070$ and $0.903 \pm 0.032$; $1.558 \pm 0.049,2.028 \pm 0.209$ and $1.987 \pm 0.155$, respectively
(Fig. 1A). Therefore, ectopic miR-145 expression significantly decreased the proliferation of A549 cells $(\mathrm{P}<0.05)$.

Abnormal miR-145 expression suppresses the invasion and migration of A549 cells. Boyden chamber Transwell assays were employed to investigate the effect of miR-145 expression on the invasive ability of A549 cells. Typical micrographs of the Transwell filters are presented in Fig. 1B. The invasive cell count (Fig. 1B and C) indicated that invasive capacity was significantly decreased in the miR-145 mimic group compared with that in the non-transfected group $(\mathrm{P}<0.001)$. The invasive cell count of the non-transfected group compared with the non-specific negative control demonstrated no significant difference $(\mathrm{P}>0.05)$. Additionally, the migratory ability of A549 cells in response to miR-145 treatment was evaluated using a wound healing assays, which identified that treatment with an miR-145 mimic decreased the percentage of wound closure compared with the non-transfected group, $24 \mathrm{~h}$ post-transfection $(\mathrm{P}<0.01$; Fig. 1D and $\mathrm{E})$. No difference in wound closure was observed between the non-specific negative control and the non-transfected group ( $\mathrm{P}>0.05$; Fig. 1E).

MMP-2 and MMP-9 expression is associated with tumor invasion and metastasis (15-17). Therefore, the present study investigated the expression levels of MMP-2 and MMP-9 in response to miR-145 treatment in A549 cells using western blot analysis (Fig. 2A). MMP-2 and MMP-9 expression was significantly decreased in the miR-145 mimic group compared with that in the non-transfected group ( $\mathrm{P}<0.05$; Fig. 2B). There was no significant difference between the non-transfected 
A

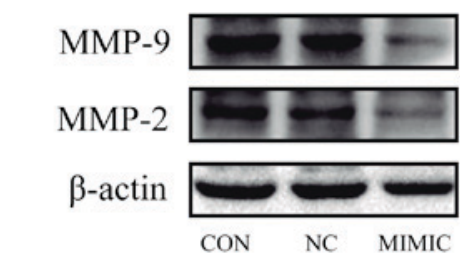

$\mathrm{C}$

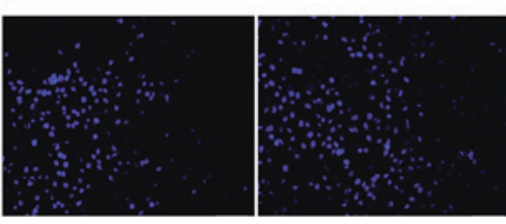

B

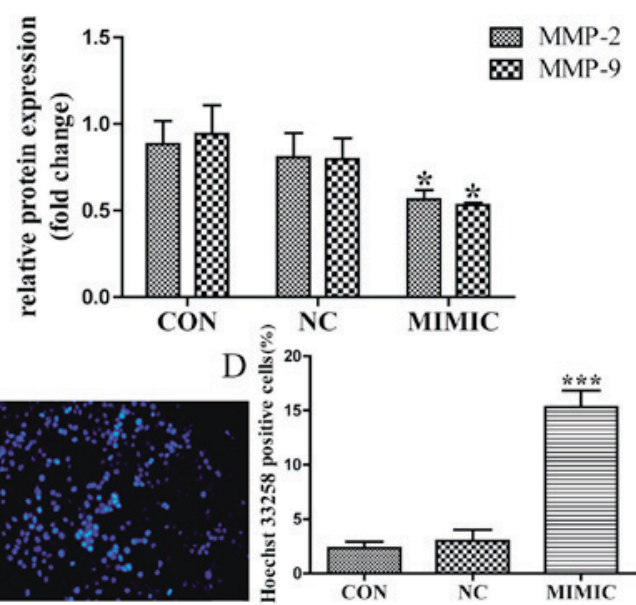

Figure 2. Increased miR-145 expression decreases the expression levels of MMP-2 and MMP-9, and induces apoptosis of A549 cells. (A) The expression levels of MMP-2 and MMP-9 as assessed by western blot analysis. (B) Quantification of the protein bands obtained by western blotting ("P $<0.05$ vs. CON group). (C) miR-145 over expression promoted the apoptosis of A549 cells. Apoptotic nuclei manifested condensed or fragmented DNA brightly stained by Hoechst 33258 (magnification, $\mathrm{x} 200$ ). (D) There were markedly more apoptotic cells in miR-145 mimic group than in the non-transfected group $\left(^{* * *} \mathrm{P}<0.001 \mathrm{vs}\right.$. CON). No difference in the apoptotic level was observed between the non-specific negative control and the non-transfected group (P>0.05). miR-145, microRNA-145; CON, non-transfected group; NC, non-specific negative control; MIMIC, miR-145 mimic group; MMP, matrix metalloproteinase.

group and the non-specific negative control in the expression of MMP-2 and MMP-9 (P>0.05; Fig. 2B). These results indicate that increased miR-145 expression inhibits the invasion and migration of A549 cells possibly by repressing the expression of MMP-2 and MMP-9.

Ectopic miR-145 expression promoted the apoptosis of A549 cells. Apoptotic cells were detected in A549 cells using the fluorescent DNA-binding dye Hoechst 33258, which stains the nuclei of normal cells blue and those of apoptotic cells bright blue or even white (Fig. 2C). The results indicated that the number of apoptotic cells was increased in the miR-145 mimic group compared with that in the non-transfected group $(\mathrm{P}<0.001$; Fig. 2D), there was no significant difference in the number of apoptotic cells between the non-transfected group and the non-specific negative control $(\mathrm{P}>0.05)$. Next, flow cytometric analysis using Annexin V-FITC/PI double staining depicted apoptosis in A549 cells (Fig. 3A). Cell apoptosis of ectopic miR-145 expression was increased and the apoptotic index was significantly higher when compared with the non-transfected group. The results indicated that ectopic miR-145 expression induced apoptosis of A549 cells $(\mathrm{P}<0.001$; Fig. 3B). There was no significant difference between the non-transfected group and the non-specific negative control $(\mathrm{P}>0.05)$. Collectively, these results indicate that deregulation of miR-145 expression promoted the apoptosis of A549 cells.

In order to elucidate the potential molecular mechanism underlying the effect of miR-145 on apoptosis of A549 cells, the expression of Bax, Bcl-2, procaspase- 3 and PARP was examined using western blot analysis. miR-145 treatment increased the expression of Bax, but led to a marked decrease in the expression level of Bcl-2. Thus, the Bax/Bcl-2 ratio was increased in the miR-145 mimic group compared with the non-transfected group $(\mathrm{P}<0.01$; Fig. $4 \mathrm{~A}$ and $\mathrm{B})$. Furthermore, miR-145 over expression promoted the cleavage of procaspase- 3 and PARP $(\mathrm{P}<0.05$; Fig. $4 \mathrm{C}$ and $\mathrm{D})$. No difference in the $\mathrm{Bax} / \mathrm{Bcl}-2$ ratio, or the cleavage of procaspase-3 or PARP were observed between the non-transfected group and the non-specific negative control group $(\mathrm{P}>0.05)$.

\section{Discussion}

NSCLC accounts for $~ 80 \%$ of all types of lung cancer and is a major cause of mortality worldwide (18). Despite advances in the medical approaches for the treatment of NSCLC, there has not been any improvement in the prognosis of patients with NSCLC over the last few decades (19). The majority of patients with NSCLC are diagnosed at advanced stages of the disease (20), which suggests that NSCLC cells have invasive and metastatic characters. Therefore, effective molecular targets for the treatment of NSCLC are required.

miRNAs have been implicated in several aspects of cancer biology, including cell proliferation, apoptosis, invasion and migration (21). Additionally, downregulation of miR-145 expression has been identified in various types of human cancer, including prostate (6), hepatocellular (22), lung (23), gallbladder (24), thyroid (25), gastric (26) and kidney (27) cancer. However, a limited number of studies have reported miR-145 as an oncogenic regulator (28-30) and that miRNAs serve crucial functions in carcinogenesis and tumor progression in NSCLC (31). miR-145 has been described as a tumor suppressor in lung cancer (32), which is consistent with the results of the present study. miR-145 may regulate the expression of thyroid cell differentiation markers, decrease cell proliferation, and induce cell cycle arrest and apoptosis, which has been demonstrated in various types of cancer $(25,33)$. A decrease in miR-145 expression may regulate a number of tumor-associated targets, including c-Myc, signal transducer and activator of transcription 1and yes-associated protein, thus promoting tumorigenesis $(34,35)$. However, the exact molecular mechanism of the action of miR-145 on the tumor biology of NSCLC remains controversial. 
A


Figure 3. Ectopic miR-145 expression increases the apoptosis rate of A549 cells. (A) Apoptosis was detected using flow cytometry at $48 \mathrm{~h}$ after transfection. (B) The apoptosis rate (Annexin V-FITC $/ \mathrm{PI}^{+}$cells) of the MIMIC group was significantly increased compared with the CON group in A549 cells $\left({ }^{* * *} \mathrm{P}<0.001\right.$ vs. CON). miR-145, microRNA-145; CON, non-transfected group; NC, non-specific negative control; MIMIC, miR-145 mimic group; FITC, fluorescein isothiocyanate; PI, propidium iodide.

A

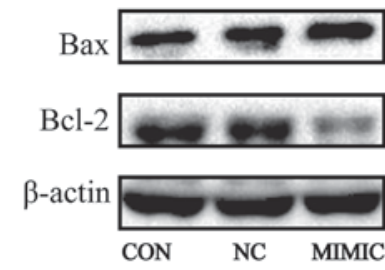

$\mathrm{C}$



B

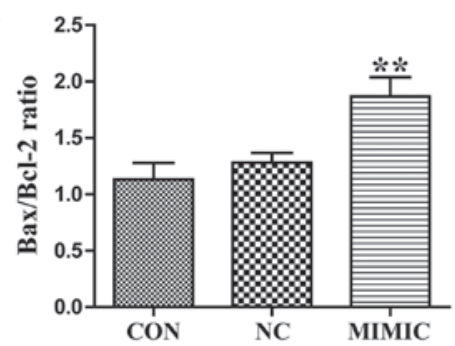

D

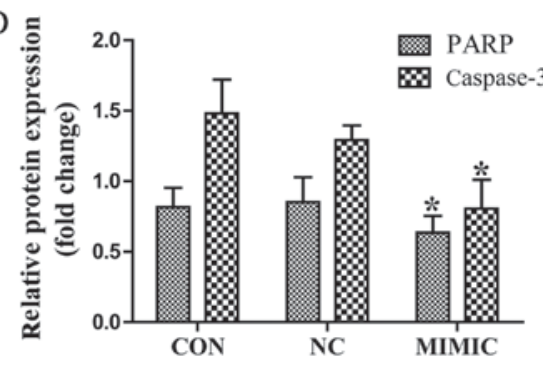

Figure 4. Deregulated miR-145 expression increases the Bax/Bcl-2 ratio and promoted the cleavage of PARP and caspase-3 in A549 cells, as assessed using western blot analysis. (A) miR-145 over expression increased the expression of Bax, but decreased the expression level of Bcl-2. (B) Quantification of the protein bands in (A). Thus, the Bax/Bcl-2 ratio was increased in the MIMIC group ( ${ }^{* *} \mathrm{P}<0.01$ vs. CON). (C and D) miR-145 over expression promoted the cleavage of caspase-3 and PARP in A549 cells ( $\mathrm{P}<0.05$ vs. CON). (D) Quantification of the protein bands PARP and Caspase-3. miR-145, microRNA-145; CON, non-transfected group; NC, non-specific negative control; MIMIC, miR-145 mimic group; Bcl-2, B-cell lymphoma 2; Bax, Bcl-2-associated X protein; PARP, poly(ADP-ribose) polymerase.

In the present study, miR-145 over expression inhibited the proliferation, invasion and migration of, and induced apoptosis in, A549 NSCLC cells. Previous studies have demonstrated that upregulation of miR-145 expression prevents glioma stem cells (GSCs) from digesting Matrigel and migrate through the pores thus decreasing the migratory ability of GSCs. Additionally, it was demonstrated that the miR-145-ATP-binding cassette transporter G2-MMP-2/9 pathway regulated the migration and invasion in GSCs (36). The results of the present study indicated that ectopic miR-145 expression may decrease the expression of MMP-2, MMP-9 and Bcl-2, and increase the expression of Bax, thus increasing the $\mathrm{Bax} / \mathrm{Bcl}-2$ ratio. Previous studies have demonstrated that miR-145 induces increased levels of pro-apoptotic proteins including caspase-3, caspase- 9 and PARP in glioma cells (37). Consistent with those studies, the results of the present study also confirmed that miR-145 over expression induced apoptosis in NSCLC cells. Caspase-3 is an executioner in caspase cascades, which are crucial steps in apoptosis-induced cell death (38). Caspase-3 activation induces the cleavage of specific substrates such as PARP, which are pivotal for the occurrence of apoptosis $(39,40)$. Furthermore, changes in the ratio of $\mathrm{Bcl}-2$ family proteins are associated with an imbalance in mitochondrial homeostasis, which leads to apoptosis $(41,42)$. Increased levels of pro-apoptotic Bax 
and/or decreased levels of anti-apoptotic Bcl-2 lead to loss of mitochondrial membrane potential, which is a critical process in the initiation of apoptosis (43).

However, there are several limitations to the present study. First, the effects of miR-145 on the cellular proliferation, invasion and migration in lung cancer was evaluated in vitro, therefore additional in vivo studies are required. Secondly, the downstream proteins and the targets of miR-145 in NSCLC cells require further investigation. Additionally, the association between miR-145 and cellular pathways requires investigation in future studies.

Taken together, the results of the present study indicate that abnormal miR-145 expression is able to suppress the proliferation and malignant phenotype of NSCLC A549 cells possibly by decreasing the expression of MMP-2 and MMP-9, the $\mathrm{Bax} / \mathrm{Bcl}-2$ ratio and the activity of the caspase -3 cascade. Therefore, miR-145 may be a promising therapeutic target for patients with NSCLC.

\section{Acknowledgements}

The present study was supported by the Natural Science Foundation of Jiangxi Province (grant no. 20132BAB205052) and the Graduate Innovation Foundation of Nanchang University (grant no. cx2016357).

\section{References}

1. Ferlay J, Shin HR, Bray F, Forman D, Mathers C and Parkin DM: Estimates of worldwide burden of cancer in 2008: GLOBOCAN 2008. Int J Cancer 127: 2893-2917, 2010.

2. Jemal A, Siegel R, Ward E, Hao Y, Xu J and Thun MJ: Cancer statistics, 2009. CA Cancer J Clin 59: 225-249, 2009.

3. Ambros V: The functions of animal microRNAs. Nature 431 350-355, 2004

4. Guz M, Rivero-Müller A, Okoń E, Stenzel-Bembenek A, Polberg K, Słomka M and Stepulak A: MicroRNAs-role in lung cancer. Disease Markers 2014: 218169, 2014.

5. Bartel DP: MicroRNAs: Target recognition and regulatory functions. Cell 136: 215-233, 2009.

6. Porkka KP, Pfeiffer MJ, Waltering KK, Vessella RL, Tammela TL and Visakorpi T: MicroRNA expression profiling in prostate cancer. Cancer Res 67: 6130-6135, 2007.

7. Nam EJ, Yoon H, Kim SW, Kim H, Kim YT, Kim JH, Kim JW and Kim S: MicroRNA expression profiles in serous ovarian carcinoma. Clin Cancer Res 14: 2690-2695, 2008.

8. Ichimi T, Enokida H, Okuno Y, Kunimoto R, Chiyomaru T, Kawamoto K, Kawahara K, Toki K, Kawakami K, Nishiyama K, et al: Identification of novel microRNA targets based on microRNA signatures in bladder cancer. Int J Cancer 125: 345-352, 2009.

9. Akao Y, Nakagawa Y and Naoe T: MicroRNA-143 and -145 in colon cancer. DNA Cell Biol 26: 311-320, 2007.

10. Sachdeva M, Zhu S, Wu F, Wu H, Walia V, Kumar S, Elble R, Watabe K and Mo YY: p53 represses c-Myc through induction of the tumor suppressor miR-145. Proc Natl Acad Sci USA 106: 3207-3212, 2009.

11. Slaby O, Svoboda M, Fabian P, Smerdova T, Knoflickova D, Bednarikova M, Nenutil R and Vyzula R: Altered expression of miR-21, miR-31, miR-143 and miR-145 is related to clinicopathologic features of colorectal cancer. Oncology 72 : 397-402, 2007

12. Campayo M, Navarro A, Viñolas N, Diaz T, Tejero R, Gimferrer JM, Molins L, Cabanas ML, Ramirez J, Monzo M and Marrades R: Low miR-145 and high miR-367 are associated with unfavourable prognosis in resected nonsmall cell lung cancer. Eur Respir J 41: 1172-1178, 2013

13. Cho WC, Chow AS and Au JS: MiR-145 inhibits cell proliferation of human lung adenocarcinoma by targeting EGFR and NUDT1. RNA Biol 8: 125-131, 2011.
14. Cho WC, Chow AS and Au JS: Restoration of tumour suppressor hsa-miR-145 inhibits cancer cell growth in lung adenocarcinoma patients with epidermal growth factor receptor mutation. Eur J cancer 45: 2197-2206, 2009.

15. Li H, Zhang K, Liu LH, Ouyang Y, Bu J, Guo HB and Xiao T: A systematic review of matrix metalloproteinase 9 as a biomarker of survival in patients with osteosarcoma. Tumour Biol 35: 5487-5491, 2014

16. Wang J, Shi Q, Yuan TX, Song QL, Zhang Y, Wei Q, Zhou L, Luo J, Zuo G, Tang M, et al: Matrix metalloproteinase 9 (MMP-9) in osteosarcoma: Review and meta-analysis. Clin Chim Acta 433: 225-231, 2014.

17. Shang HS, Chang JB, Lin JH, Lin JP, Hsu SC, Liu CM, Liu JY, Wu PP, Lu HF, Au MK and Chung JG: Deguelin inhibits the migration and invasion of U-2 OS human osteosarcoma cells via the inhibition of matrix metalloproteinase-2/-9 in vitro. Molecules 19: 16588-16608, 2014.

18. Li W, Wang Y, Zhang Q, Tang L, Liu X, Dai Y, Xiao L, Huang S, Chen L, Guo Z, et al: MicroRNA-486 as a biomarker for early diagnosis and recurrence of non-small cell lung cancer. PLoS One 10: e0134220, 2015.

19. Verdecchia A, Francisci S, Brenner H, Gatta G, Micheli A, Mangone L and Kunkler I; EUROCARE-4 Working Group: Recent cancer survival in Europe: A 2000-02 period analysis of EUROCARE-4 data. Lancet Oncol 8: 784-796, 2007.

20. Molina JR, Yang P, Cassivi SD, Schild SE and Adjei AA: Non-small cell lung cancer: Epidemiology, risk factors, treatment, and survivorship. Mayo Clin Proc 83: 584-594, 2008.

21. Angulo M, Lecuona E and Sznajder JI: Role of MicroRNAs in lung disease. Arch Bronconeumol 48: 325-330, 2012.

22. Yang XW, Zhang LJ, Huang XH, Chen LZ, Su Q, Zeng WT, Li W and Wang Q: miR-145 suppresses cell invasion in hepatocellular carcinoma cells: miR-145 targets ADAM17. Hepatol Res 44: 551-559, 2014

23. Ling DJ, Chen ZS, Zhang YD, Liao QD, Feng JX, Zhang XY and Shi TS: MicroRNA-145 inhibits lung cancer cell metastasis. Mol Med Rep 11: 3108-3114, 2015.

24. Letelier P, García P, Leal P, Álvarez H, Ili C, López J, Castillo J, Brebi P and Roa JC: miR-1 and miR-145 act as tumor suppressor microRNAs in gallbladder cancer. Int J Clin Exp Pathol 7: 1849-1867, 2014.

25. Boufraqech M, Zhang L, Jain M, Patel D, Ellis R, Xiong Y, He M, Nilubol N, Merino MJ and Kebebew E: miR-145 suppresses thyroid cancer growth and metastasis and targets AKT3. Endocr Relat Cancer 21: 517-531, 2014.

26. Gao P, Xing AY, Zhou GY, Zhang TG, Zhang JP, Gao C, Li H and Shi DB: The molecular mechanism of microRNA-145 to suppress invasion-metastasis cascade in gastric cancer. Oncogene 32: 491-501, 2013.

27. Papadopoulos EI, Yousef GM and Scorilas A: Cytotoxic activity of sunitinib and everolimus in Caki-1 renal cancer cells is accompanied by modulations in the expression of apoptosis-related microRNA clusters and BCL2 family genes. Biomed Pharmacother 70: 33-40, 2015.

28. Yuan W, Sui C, Liu Q, Tang W, An H and Ma J: Up-regulation of microRNA-145 associates with lymph node metastasis in colorectal cancer. PLoS One 9: e102017, 2014.

29. Li Z, Gu X, Fang Y, Xiang J and Chen Z: microRNA expression profiles in human colorectal cancers with brain metastases. Oncol Lett 3: 346-350, 2012.

30. Arndt GM, Dossey L, Cullen LM, Lai A, Druker R, Eisbacher M, Zhang C, Tran N, Fan H, Retzlaff K, et al: Characterization of global microRNA expression reveals oncogenic potential of miR-145 in metastatic colorectal cancer. BMC Cancer 9: 374, 2009.

31. Du L and Pertsemlidis A: microRNA regulation of cell viability and drug sensitivity in lung cancer. Expert Opin Biol Ther 12: 1221-1239, 2012.

32. Lu Y, Govindan R, Wang L, Liu PY, Goodgame B, Wen W, Sezhiyan A, Pfeifer J, Li YF, Hua X, et al: MicroRNA profiling and prediction of recurrence/relapse-free survival in stage I lung cancer. Carcinogenesis 33: 1046-1054, 2012.

33. Xu Q, Liu LZ, Qian X, Chen Q, Jiang Y, Li D, Lai L and Jiang BH: MiR-145 directly targets p70S6K1 in cancer cells to inhibit tumor growth and angiogenesis. Nucleic Acids Res 40: 761-774, 2012.

34. Chen Z, Zeng H, Guo Y, Liu P, Pan H, Deng A and Hu J: miRNA-145 inhibits non-small cell lung cancer cell proliferation by targeting c-Myc. J Exp Clin Cancer Res 29: 151, 2010. 
35. Gregersen LH, Jacobsen AB, Frankel LB, Wen J, Krogh A and Lund AH: MicroRNA-145 targets YES and STAT1 in colon cancer cells. PLoS One 5: e8836, 2010.

36. Shi L, Wang Z, Sun G, Wan Y, Guo J and Fu X: miR-145 inhibits migration and invasion of glioma stem cells by targeting ABCG2. Neuromolecular Med 16: 517-528, 2014.

37. Rani SB, Rathod SS, Karthik S, Kaur N, Muzumdar D and Shiras AS: MiR-145 functions as a tumor-suppressive RNA by targeting Sox9 and adducin 3 in human glioma cells. Neuro Oncol 15: 1302-1316, 2013.

38. Ding L, Wu JP, Xu G, Zhu B, Zeng QM, Li DF and Lu W: Lentiviral-mediated RNAi targeting caspase-3 inhibits apoptosis induced by serum deprivation in rat endplate chondrocytes in vitro. Braz J Med Biol Res 47: 445-451, 2014.

39. Norbury CJ and Zhivotovsky B: DNA damage-induced apoptosis. Oncogene 23: 2797-2808, 2004.
40. Soldani C and Scovassi AI: Poly(ADP-ribose) polymerase-1 cleavage during apoptosis: An update. Apoptosis 7: 321-328, 2002.

41. Orrenius S: Mitochondrial regulation of apoptotic cell death. Toxicol Lett 149: 19-23, 2004.

42. Scorrano L and Korsmeyer SJ: Mechanisms of cytochrome c release by proapoptotic BCL-2 family members. Biochem Biophys Res Commun 304: 437-444, 2003.

43. Meeran SM and Katiyar SK: Grape seed proanthocyanidins promote apoptosis in human epidermoid carcinoma A431 cells through alterations in Cdki-Cdk-cyclin cascade, and caspase-3 activation via loss of mitochondrial membrane potential. Exp Dermatol 16: 405-415, 2007.

(i) () () This work is licensed under a Creative Commons Attribution-NonCommercial-NoDerivatives 4.0 International (CC BY-NC-ND 4.0) License. 